\title{
MENJAGA KEARIFAN LOKAL DENGAN MEMBUDAYAKAN TRADISI BASUNTING BAGI MARAPULAI DALAM ADAT PERKAWINAN DI KANAGARIAN INDERAPURA KECAMATAN PANCUNG SOAL KABUPATEN PESISIR SELATAN
}

\author{
Febrina Khairunnisa ${ }^{1}$, Refisa Ananda ${ }^{2}$ \\ Program Studi Perpustakaan dan Ilmu Informasi, Fakultas Bahasa dan Seni \\ Universitas Negeri Padang \\ Febrinakhairunnisa24@gmail.com \\ refisaananda@fbs.unp.ac.id
}

\begin{abstract}
This research is motivated by the unique tradition of a wedding or baralek party in Kanagarian Inderapura, Pancung Soal Subdistrict, Pesisir Selatan District, in Kanagarian Inderapura, the bridegroom or bridegroom starts to use suntiang as a bride in Minangkabau. This article was written to describe the tradition of basuntiang for marapulai in customary marriages in Kanagarian Inderapura, Pancung Soal Subdistrict, Pesisir Selatan District. The benefits of writing this article are expected to be able to provide more knowledge of the marital traditions that exist in the South Coastal District. The research method used is descriptive qualitative research subjects are citizens of Kanagarian Inderapura, Savings of Pancung Problem in the South Coastal District of Pesisir. Data collection techniques through interviews. The result of this research is to preserve local wisdom by cultivating the tradition of basuntiang for marapulai in customary marriages in Kanagarian Inderapura, Pancung Soal Subdistrict, Pesisir Selatan District which is different from other regions in Minangkabau. In other areas marapakai mamakai saluak, but in the Nagari area Inderapura started using suntiang as a head covering when holding a wedding party. The use of suntiang the groom (marapulai) is a custom that has been passed down through generations and inherited from ancestors.
\end{abstract}

Keywords:basuntiang, marriage, local wisdom

\section{PENDAHULAN}

Indonesia merupakan negara kepulauan, tentunya banyak suku bangsa dan bermacam budaya salah satunya Minangkabau terkenal dengan berbagai macam adat dan tradisi yang beranekaragam, seperti kata pepatah Lain Lubuak, Lain ikannyo, lain padang, lain pulo hilalangnyo. seperti adat perkawinan yang memiliki tata cara yang unik dan menarik. Selain itu, pelaksanaannya di masing-masing daerah juga berbeda-beda, karena setiap daerah memiliki cara dan prosedur tersendiri yang sesuai dengan adat-istiadat yang dianut oleh masyarakat tersebut dalam melaksanakan upacara perkawinan. Meskipun terdapat perbedaan dalam pelaksanaan upacara perkawinan, tetapi mereka memiliki tujuan dan maksud yang sama, yaitu mempersatukan seorang laki-laki dengan seorang perempuan untuk membina sebuah keluarga yang baru.

Kabupaten Pesisir Selatan terletak di pinggir pantai, dengan garis pantai sepanjang 218 kilometer topografinya terdiri dari dataran, gunung dan perbukitan yang merupakan perpanjangan gugusan Bukit Barisan. Berdasarkan penggunaan lahan, 45,29 persen wilayah terdiri dari hutan, termasuk kawasan Taman Nasional Kerinci Seblat, Cagar Alam Koto XI Tarusan, dan rawa gambut Nama Pesisir Selatan berasal dari 
nama daerah ini pada masa penjajahan Belanda, afdeling zuid beneden landen (dataran rendah bagian selatan). (Dhakide, 2003 122-125)

Sebelum Abad ke-16, wilayah Pesisir Selatan merupakan daerah sepanjang pesisir pantai Sumatra Barat yang terdiri dari rawa-rawa dataran rendah dan bebukitan yang sudah berpenghuni. Penghuninya waktu itu masih sangat sedikit. Mereka berasal dari berbagai negeri asal. Mereka tinggal di sepanjang pesisir pantai sebagai nelayan. Sebagian mereka datang dari pedalaman Sumatra atau hulu sungai Batang Hari. Sebagian lagi penyebaran dari daerah Indojati atau Air Pura. Dan sebagian dari mereka adalah orang-orang yang dikenal sebagai Orang Rupit pelarian dari daerah Sungai Pagu Muara Labuh dan sekitarnya yang kemudian menyeberang ke Pulau Pagai(Dhakide, 2003 122-125).

Tiga wilayah utama yang ada di Kabupaten Pesisir Selatan, Tarusan (Bayang, Salido Painan) Bandar Sepuluh (Batangkapas, Surantih, Kambang, Palangai, Air Haji), Renah Indojati (Inderapura, Tapan, Lunang Silaut).

Pancung Soal adalah sebuah Kecamatan di Kabupaten Pesisir Selatan, Sumatera Barat, Indonesia. Secara administratif wilayahnya adalah sebagian wilayah Nagari Inderapura yang merupakan pusat kerajaan inderapura. Sebagian besar wilayah Inderapura termasuk dalam kecamatan Airpura, yaitu kecamatan pemekaran yang sebelumnya merupakan bagian dari Kecamatan Pancung Soal.

Setiap kecamatan ataupun kenagarian di Pesisir Selatan mempunyai kebudayaan dan tradisi yang menarik, turun temurun dari masa lalu sampai sekarang misalnya adat-istiadat dalam perkawinan. Adat istiadat perkawinan secara umum mempunyai banyak kesamaan antara satu kecamatan atau nagari dengan nagari lainnya terutama dalam simbol-simbol adat ataupun maksud yang terkandung dalam setiap bagian adat istiadat dan tata cara perkawinan.

Namun demikian ada juga yang berbeda khususnya nagari di Inderapura Kabupaten Pancung Soal Pesisir Selatan Sumatera Barat adat-istiadat perkawinannya berbeda dari kanagarian lainnya. Salah satu simbol atau bagian adat yang berbeda terletak pada pakaian adat/ tata rias pengantin pria (marapulai). Di nagari Inderapura dalam adat-istiadat perkawinan pengantin pria juga memakai suntiang layaknya pengantin wanita.

pemakaian suntiang pada pengantin pria (marapulai) merupakan adat istiadat turun temurun dan nenek moyang terdahulu. Asal usul suntiang marapulai berawal dari sejarah Adityawarman yang ingin menguasai kerajaan Indojati (Inderapura Silaut) yang berada di Darek. Saat Adityawarman utusan raja Jawa Majapahit sampai di Darek pada tahun 1350. Adityawarman disambut secara permai, meriah, secara adat dengan tari-tarian. Adityawarman didandani secara adat dan dipakaikan suntiang. Dalam penyambutan kedatangan Adityawarman itulah awal mula marapulai memakai suntiang, dimana pada waktu itu suntiang merupakan mahkota dan aksesoris yang indah. Karena disambut secara baik dan juga ditawarkan adityawarman tidak jadi ingin menguasai kerajaan indojati. Adityawarman menyukain seorang gadis dan adityawarman menikahi gadis tersebut, namun setekah Setelah beberapa bulan mereka menikah, Datuk Parpatih mengeluarkan peraturan adat yang berlaku di Darek yaitu Adityawarman selaku sumando turun setangkik tanggo dan Datuk Parpatih selaku basumando naik setangkik tanggo. Maka menurut adat yang berlaku di Darek Adityawarman tidak bisa 
berkuasa di Darek. Jadi yang berkuasa di Darek adalah Datuk Parpatih nan Sabatang (Sutan Balun). Untuk mengenang peristiwa bersejarah inilah suntiang marapulai menjadi ketetapan adat-istiadat Inderapura. Siapa pun yang ingin menjadi sumando (ipar) di Inderapura harus memakai suntiang (Yodinda f. , 2017: 2-4)

Suntiang secara umum sudah dikenal sebagai aksesoris utama bagi seorang pengantin wanita Minang saat menjalankan prosesi adat perkawinan. Suntiang biasa dipakai di kepala pengantin wanita (anak daro). Suntiang adalah perhiasan kepala untuk mempercantik penampilan dan biasanya perhiasan di kepala ini hanya dipakai oleh pengantin perempuan (Nursyirwan, 2009: 3)

Pada zaman dahulu berat suntiang mencapai beberapa kilogram karena terbuat dari besi-besi, ada yang terbuat dari emas, berbentuk hiasan bunga-bunga dan harus ditancapkan satu persatu pada rambut mempelai wanita. Dahulu suntiang beratnya bisa mencapai berkilo kilo dan harus dipakai di atas kepala selama pesta berlangsung, membuat calon pengantin perempuan yang disebut 'anak daro' banyak yang tidak sanggup menjalankannya. Namun semakin modernnya fashion, suntiang pun sudah dimodifikasi sedemikian bentuk. Sekarang suntiang lebih ringan dan hampir seperti menggunakan bando biasa, sehingga anak daro lebih santai dan bergerak leluasa tanpa keluhan sakit kepala.

Di Kanagarian Inderapura suntiang yang dipakai pengantin pria (marapulai) dan pengantin wanita (anak daro) bentuknya sedikit berbeda, perbedaan antara suntiang anak daro dengan marapulai yaitu Corak suntiang dan tinggi suntiang yang berbeda, tetapi suntiang yang dipakai merupakan suntiang gadang yang sudah dimodifikasi tetapi banyak meninggalkan unsur adat-istiadat setempat. dikarenakan suntiang marapulai yang lama (yang asli) tidak ada lagi yang menyimpan, sehingga bentuk dari suntiang yang baru sudah tidak menyerupai yang lama lagi, akan tetapi bukan berarti makna dari pemakaian suntiang ini berubah.

Berdasarkan uraian di atas penulis tertarik untuk lebih mendalami tentang "Menjaga kearifan lokal dengan membudayakan Tradisi Basunting Bagi Marapulai Dalam Adat Perkawinan di Kanagarian Inderapura Kecamatan Pancung Soal Kabupaten Pesisir Selatan"

\section{METODE}

Penelitian ini merupakan jenis penelitian kualitatif. Penelitian kualitatif adalah penelitian yang menghasilkan data deskriptif berupa kata-kata tertulis atau lisan dari orang-orang dan perilaku yang dapat diamati (Lexy J, 2009:248).

Sesuai dengan judul yang diangkat oleh peneliti yaitu menjaga kearifan lokal dengan membudayakan tradisi basuntiang bagi marapulai dalam adat perkawinan di Kanagarian Inderapura Kecamatan Pancung Soal Kabupaten Pesisir Selatan, maka penelitian berlokasi di Kanagarian Inderapura Kecamatan Pancung Soal Kabupaten Pesisir Selatan. Jenis penelitian yang dilakukan adalah penelitian lapangan, yaitu penelitian langsung ke kanagarian inderapura untuk mengetahui secara jelas bagaimana tradisi basuntiang bagi marapulai ini dilaksanakan dalam acara perkawinan di Kanagarian Inderapura ini.

Teknik mengumpulkan data yaitu melalui observasi dan pengamatan. Observasi adalah kemampuan seseorang untuk menggunakan pengamatanya melalui hasil kerja panca indra dibantu dengan pancaindra lainnya, seperti telingga, penciuman, mulut dan kulit (Bungin, 2009:115).

Pada penelitian ini peneliti melakukan observasi terhadap warga yang ada di kanagarian inderapura kecamatan pesisir 


\section{7 | JURNAL ILMU BUDAY A}

selatan yang sedang melaksanakan acara baralek atau yang lebih dikenal dengan pesta pernikahan, acara pernikahan antara mailid fransiska dengan pasangan mempelai laki-lakinya zul luqman.

Teknik pengumpulan data yang selanjut nya yaitu dengan wawancara. Wawancara digunakan sebagai teknik pengumpulan data apabila peneliti ingin melakukan studi pendahuluan untuk menemukan masalah yang harus diteliti dan apabila peneliti ingin mengetahui halhal dari responden yang lebih mendalam dan jumlah respondennya sedikit/ kecil. Wawancara dapat dilakukan secara terstruktur (peneliti telah mengetahui dengan pasti tentang informasi apa yang akan diperoleh) maupun tidak terstruktur (peneliti tidak menggunakan pedoman wawancara yang telah tersusun secara sistematis dan lengkap sebagai pengumpul datanya) dan dapat dilakukan secara langsung (tatap muka) maupun secara tidak langsung (melalui media seperti telepon) (Sugiyono, 2012:8).

Wawancara dilakukan dengan warga yang hadir dalam acara baralek tersebut, dengan informan yang bernama bapak masri. Peneliti menanyakan kepada informan bagaimana tradisi basunting di kenagarian inderapura kecamatan pancung soal kabupaten pesisir selatan.

\section{HASIL DAN PEMBAHASAN}

Setiap kecamatan ataupun Kenagarian di Pesisir Selatan mempunyai kebudayaan dan tradisi yang menarik, tradisi yang turun temurun dari masa lalu sampai sekarang misalnya adat-istiadat dalam pelaksanaan perkawinan. Adat istiadat perkawinan secara umum mempunyai banyak kesamaan antara satu kecamatan atau nagari dengan nagari lainnya terutama dalam simbol-simbol adat ataupun maksud yang terkandung dalam setiap bagian adat istiadat dan tata cara perkawinan. Namun dalam hal ini berbeda khususnya nagari di Inderapura kabupaten pancung soal Pesisir Selatan Sumatera Barat adat-istiadat perkawinannya berbeda dari kanagarian lainnya. Salah satu simbol atau bagian adat yang berbeda terletak pada pakaian adat/ tata rias pengantin pria (marapulai). Di nagari Inderapura dalam adat-istiadat perkawinan pengantin pria juga memakai suntiang layaknya pengantin wanita.

Tradisi perkawianan atau yang biasa disebut dengan baralek di nagari Inderapura Kecamatan Pancung Soal Kabupaten Pesisir Selatan berbeda dengan daerah lain yang ada di Minangkabau. Di daerah lain marapulai memakai saluak, tetapi di daerah Nagari Inderapura Kecamatan Pancung Soal Kabupaten Pesisir Selatan ini marapulai nya memakai suntiang sebagai penutup kepala ketika mengadakan pesta perkawinan. Suntiang dikenal sebagai aksesoris utama bagi seorang pengantin wanita Minang saat menjalankan prosesi adat perkawinan. Suntiang biasa dipakai di kepala pengantin wanita (anak daro), namun di kanagarian inderapura ini tidak hanya pengantin wanita (anak daro) saja yang memakai suntiang, akan tetapi pengantin laki-laki (marapulai) juga memakai suntiang.

Pemakaian suntiang pengantin pria (marapulai) merupakan adat istiadat nenek moyang terdahulu. Asal usul suntiang marapulai berawal dari sejarah Adityawarman yang ingin menguasai kerajaan Indojati (Inderapura Silaut) yang berada di Darek. Saat Adityawarman utusan raja Jawa Majapahit sampai di Darek pada tahun 1350. Adityawarman disambut secara permai, meriah, secara adat dengan tari-tarian. Adityawarman didandani secara adat dan dipakaikan suntiang. Dalam penyambutan kedatangan Adityawarman itulah awal mula marapulai memakai suntiang, dimana pada waktu itu suntiang merupakan mahkota dan 


\section{8 | JURNAL ILMU BUDAY}

aksesoris yang indah. Karena disambut secara baik dan juga ditawarkan mengawini Gadih Jamilan yang berusia 17 tahun, sehingga Adityawarman yang awalnya ingin menguasai kerajaan Indojati akhirnya berubah pikiran dan menghentikan niat untuk menguasai kerajaan Indojati. Setelah beberapa bulan mereka kawin, Datuk Parpatih mengeluarkan peraturan adat yang berlaku di Darek yaitu Adityawarman selaku sumando (ipar) turun setangkik tanggo dan Datuk Parpatih selaku basumando naik setangkik tanggo. Maka menurut adat yang berlaku di Darek Adityawarman tidak bisa berkuasa di Darek. Jadi yang berkuasa di Darek adalah Datuk Parpatih nan Sabatang (Sutan Balun). Untuk mengenang peristiwa bersejarah inilah suntiang marapulai menjadi ketetapan adat-istiadat Inderapura. Siapa pun yang ingin menjadi sumando (ipar) di Inderapura harus memakai suntiang (Yodinda f. , 2017: 2-4)

Suntiang yang dipakai mempelai laki-laki (Marapulai) coraknya berbeda dengan suntiang yang dipakai mempelai perempuan (Anak Daro). Suntiang yang dipakai Marapulai tinggi lonjongnya lebih rendah dibandingkan dengan suntiang Anak Daro. Kemudian, lebarnya pun lebih kecil ketimbang suntiang Anak Daro. Corak pernak pernik suntiang marapulai lebih besar motifnya dibandingkan dengan suntiang yang dipakai anak daro, corak yang lebih besar ini memiliki arti atau makna bahwasanya seseorang laki-laki yang telah menikah memiliki tanggung jawab yang besar atas keluarganya besok, dan hal ini juga menunjukkan bahwa sosok laki-laki yang memiliki prinsip dan tegas dalam membina rumah tangganya.

Sedangkan suntiang Anak Daro lebih tinggi dan lebih lebar dibandingkan suntiang marapulai, dan motif suntiang anak daro lebih halus dibandingkan suntiang marapulai, suntiang yang lebih besar dan lebih tinggi ini dimaknai dengan besarnya tanggung jawab yang akan dipikul oleh anak daro baik itu tanggung jawab dalam rumah tangga nya, keluarga maupun lingkungannya. Didalam rumah tangga seorang istri berperan sebagia seorang istri bagi suaminya dan ibu bagi anak-anaknya yang harus menjaga keutuhan rumah tangga nya, yang bermanfaat bagi kehidupan bermasyarakat. Dan di dalam masyarakat, perempuan yang sudah menikah akan diberi julukan bundo kanduang, bundo kanduang adalah seorang perempuan yang memiliki sifat arif dan bijaksana yang menjadi tauladan bagi anaknya.

$\begin{array}{rrr}\text { Tradisi } & \text { Marapulai memakaian } \\ \text { suntiang di } & \text { Kanagarian } & \text { Inderapura }\end{array}$
Kecamatan Pancung Soal Kabupaten Pesisir Selatan ini untuk mengahargai arwah ninik mamak dan datuak yang terdahulu, karena marapulai di Kanagarian Inderapura ini tidak memakai saluak pada saat resepsi pernikahan dilaksanakan . Sebab, suntiang adalah bentuk kemegahan dan identitas diri sebagai urang sumando bagi mamak rumah. pengantin laki-laki (Marapulai) memakai Suntiang atau rias yang dikenakan saat arak-arakan turun dari rumah bako atau disebut juga dengan turun bako. Turun bako ini mempelai dibawa kerumah bako (etek dari Saudari Perempuan ayah bagi mempelai) untuk di rias mengenakan pakaian pengantin. Arakarakan kedua mempelai tersebut diiringi dengan Badiki (berzikir) atau berzanji dengan menambuh rebana yang merupakan musik tradisi yang turun termurun sejak agama Islam masuk ke Inderapura.

Tradisi basuntiang bagi marapulai ini memiliki makna tersendiri oleh masyarakat Inderapura, yaitu dengan menggunakan suntiang yang berat pada marapulai itu menandakan akan mulai nya babak baru dalam kehidupan mereka, suntiang yang besar dan lumayan berat 


\section{9 | JURNAL ILMU BUDAY}

pada dahulunya ini menandakan sebagai bahwasanya sebagai laki-laki yang sudah memiliki keluarga akan memiliki tanggung jawab yang besar. Tanggung jawab seorang suami tidak hanya memberian nafkah kepada istri ataupun keluarganya saja, akan tetapi juga bertanggung jawab atas mendidik, membimbing, dan menjadi suri tauladan bagi anak dan kemenakannya.

Tradisi basunting bagi marapulai di kanagarian inderapura kecamatan pancung soal kabupaten Pesisir Selatan ini harus dijaga dengan baik, tradisi ini harus terus berjalan dan dibudayakan terus menerus, agar tradisi ini tidak hilang maka sangat butuh peran anak- anak muda atau anak milenial sebagai penerus generasi bangsa yang harus menjaga budaya dan tradisi ini. Kita sebagai anak milenial harus memiliki rasa bangga akan semua tradisi-tradisi yang ada di indonesia ini, kalau bukan kita sebagai anak-anak muda ini yang mejaga sebuah tradisi lalu siapa lagi yang akan menjaganya. Kita tidak bisa bergantung pada orang tua terdahulu, karna tidak dapat dipungkiri bahwasanya orang tua pastinya akan meninggal kan kita, dan jangan sampai tradisi ini hilang bersama orang tua terdahulu kita.

Dengan menjaga tradisi ini kita sebagai anak bangsa harus selalu menjaga kearifan lokal yang ada di negara kita, salah satunya dengan menjaga tradisitradisi yang ada disetiap wilayah pada semua penjuru Indonesia ini. Dengan menjaga kerifan lokal ini tentunya kita akan bisa memberikan warisan kepada anak cucu kita kelak, agar mereka juga dapat merasakan apa yang kita rasakan dahulunya, merasakan bagaimana indahnya kearifan lokal kita, budaya yang begitu banyak yang ada dinegara kita, dan semua itu harus dimulai dengan kita menjaga nya dimulai dari sekarang.

\section{KESIMPULAN}

Tradisi perkawianan atau yang biasa disebut dengan baralek di nagari Inderapura Kecamatan Pancung Soal Kabupaten Pesisir Selatan berbeda dengan daerah lain yang ada di Minangkabau. Di daerah lain marapulai memakai saluak, tetapi di daerah nagari Inderapura Kecamatan Pancung Soal Kabupaten Pesisir Selatan ini marapulai nya memakai suntiang sebagai penutup kepala ketika mengadakan pesta perkawinan. Suntiang dikenal sebagai aksesoris utama bagi seorang pengantin wanita Minang saat menjalankan prosesi adat perkawinan.

Pemakaian suntiang pengantin pria (marapulai) merupakan adat turun menurun dari nenek moyang terdahulu. Tradisi basuntiang bagi marapulai ini memiliki makna tersendiri oleh masyarakat Inderapura, yaitu dengan menggunakan suntiang yang berat pada marapulai itu menandakan akan mulai nya babak baru dalam kehidupan mereka, suntiang yang besar dan lumayan berat pada dahulunya ini menandakan sebagai bahwasanya sebagai laki-laki yang sudah memiliki keluarga akan memiliki tanggung jawab yang besar. Tanggung jawab seorang suami tidak hanya memberian nafkah kepada istri ataupun keluarganya saja, akan tetapi juga bertanggung jawab atas mendidik, membimbing, dan menjadi suri tauladan bagi anak dan kemenakannya. 


\section{DAFTAR PUSTAKA}

Arafah, Burhanuddin, Hasyim, Muhammad. 2019. Linguistic functions of emoji in social media communication. Opción, Vol. 35, No. 24, 558-574

Ariesta, F.W. 2019. Nilai Moral dalam Lirik Dolanan Cublak-Cublak Suweng. Jurnal Ilmu Budaya. Vol. 7, No. 2, 188-192

Berita.pesisirselatankab. (n.d.). Retrieved Desember jumat, 2019, from berita.pesisirselatankab: https://berita.pesisirselatankab.go.i d/page/detail/kecamatan--nagari Diakses Pada 21 Desember 2019

Bungin, H. B. (2009:115). Penelitian kualitatif. Jakarta: Cet.lll; Jakarta: Kencana Prenada Media Group.

Dhakide, D. (2003). Profil Daerah: kabupaten dan Kota Jilid 2.

Penerbit Kompas.

Hasyim, Muhammad. 2014. Konstruksi Mitos dan Ideologi dalam Teks Iklan Komersial Televisi: Suatu Analisis Semiologi. Disertasi. Makassar: Program Pascarajana Universitas Hasanuddin.

Hasyim, Muhammad Dr., Akhmar, A.M., Kuswarini, P., Wahyuddin. 2019. Foreign Tourists' Perceptions of Toraja as a Cultural Site in South Sulawesi, Indonesia. African Journal of Hospitality, Tourism and Leisure. Volume 8 (3)

Hasyim, Muhammad. 2017. The Metaphor of Consumerism. Journal of Language Teaching and Research, Vol. 8, No. 3, pp. 523-530

Hasyim, M., Prasuri Kuswarini, P., Kaharuddin. 2020. Semiotic Model for Equivalence and NonEquivalence in Translation. Humanities \& Social Sciences Reviews. 8 (3), 381-391.
Intan, Tania. 2018. Narator Sebagai Penyampai Kritik Sosial Dalam Novel Moha Le Fou Moha Le Sage Karya Tahar Ben Jelloun. Jurnal Ilmu Budaya. 6 (2), 207-220

Kaharuddin, Hasyim, Muhammad. 2020. The Speech Act of Complaint: Socio-Cultural Competence Used by Native Speakers of English and Indonesian. International Journal of Psychosocial Rehabilitation, 24 (06), 14016-14028

Kuswarini, Prasuri, Muhammad Hasyim, M., Chotimah, Irma N.H. 2020. Othering The Self as A Form of Mimicry in The English Translation of Hirata's Laskar Pelangi. Journa of Critical Reviews. Vol 7, Issue 19, 12861295

Lexy J, M. (2009:248). Metodologi Penelitian Kualitatif. Bandung: PT. Remaja Rosdakarya.

Maknun, T., Hasjim, M., Muslimat, M., and Hasyim, M. 2019. The form of the traditional bamboo house in the Makassar culture: A cultural semiotic study. Semiotica. In press. https://doi.org/10.1515/sem-2017$\underline{0162}$

Nofitasari, D.V., Rosyadi,I., Muslimin, M., Hendrawan, R., Yudistio,K., Sa'adah, Z., Dharmawan, A.S. 2020. Harmonisasi Masyarakat Tengger dalam Upacara Yadnya Karo. Jurnal Ilmu Budaya. Vol. 8., No. 1, 140-145.

Nursyirwan, E. (2009: 3). Eksistensi Pakaian Bundo Kanduang Dalam Upacara Adat di Kota Payakumbuh. Padang: Bpsnt Padang Press.

Saputra, W.I., Hasyim, Muhammad., Junus, Fierenziana G. 2020. Perspektif Media Prancis dalam Pemberitaan Pencemaran Air di 


\section{1 | JURNAL ILMU BUDAY A}

Volume 8, Nomor 2, Tahun 2020

Indonesia. Al-Munzir, Vol. 13. No. 1, 19-34.

Shintya Putri Setiowati. 2020. Pembentukan Karakter Anak Pada Lagu Tokecang, Jawa Barat. Jurnal Ilmu Budaya. 8 (1), 172-177

Sugiyono. (2012). Metode Penelitian Kuantitatif Kualitatif dan $R \& D$. Bandung: Alfabeta

Yodinda, f. (2017). Bentuk, Fungsi Dan Makna Ornamen Suntiang Marapulai Di Inderapura Pesisir Selatan.Bentuk,

Fungsi Dan Makna Ornamen

Suntiang Marapulai Di Inderapura Pesisir Selatan. Universitas Negeri Padang. 